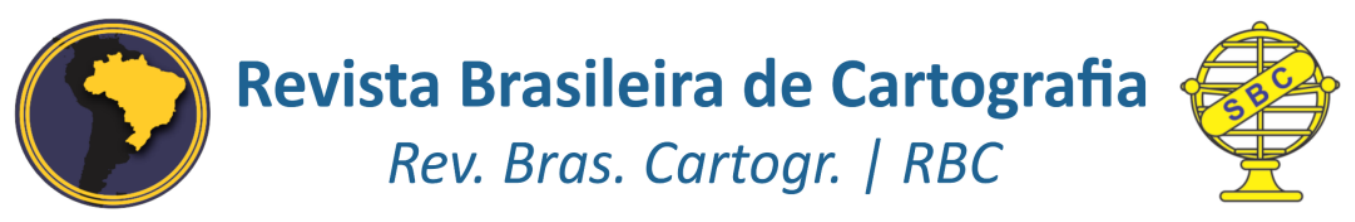

DOI: http://dx.doi.org/10.14393/rbcv71n4-50377

\title{
Parâmetros de Fabricação de Símbolos para Mapas Táteis
}

\author{
Manufacturing Parameters for Tactile Map Symbols
}

Gabriel Moraes de Bem ${ }^{1}$

Regiane Trevisan Pupo ${ }^{2}$

Recebido em setembro de 2019.

Aprovado em novembro de 2019.

\begin{abstract}
RESUMO
No que diz respeito à acessibilidade espacial, compreensão do ambiente e entendimento de trajetos a serem percorridos por pessoas com deficiência visual, os mapas táteis são uma importante ferramenta para auxiliar o planejamento prévio da rota a ser realizada por seus usuários. Embora, de acordo com a Norma Brasileira Regulamentadora, NBR 9050:2015, que trata da acessibilidade a edificações, mobiliário, espaços e equipamentos urbanos, a instalação de mapas táteis seja uma exigência a ser cumprida em edificações de acesso público, há poucas orientações quanto à sua fabricação, caracterização dos relevos táteis. Além disso, dentre os pesquisadores da área, há divergências entre as especificações dos elementos. Essa pesquisa, por sua vez, contribui tanto com a inclusão social no que diz respeito ao ensino de geografia, linguagem cartográfica e orientação espacial, uma vez que, a partir do agrupamento de parâmetros adotados no Brasil, no âmbito da cartografia tátil e no exterior, relacionados tanto à cartografia quanto à fabricação de mapas para edificações, traz uma síntese dos elementos já utilizados. Além disso, desenvolve, avalia e valida, por intermédio de testes com profissionais revisores de material braile, novos parâmetros a serem compartilhados por desenvolvedores de mapas táteis. Os parâmetros apresentados contemplam símbolos, letras, linhas, texturas e braile, caracterizando-os no que diz respeito à espessura, formato, elevação em relação à superfície e padronagens de representação, resultando num padrão de representação e fabricação de símbolos para mapas táteis.
\end{abstract}

PALAVRAS-CHAVE: Matriz tátil. Fabricação digital. Deficiente visual.

\begin{abstract}
Regarding spatial accessibility, the understanding of the environment and of the paths to be traveled by visually impaired people, tactile maps are an important tool in order to help to the prior planning of the route to be performed by its users. According to the Brazilian Regulatory Standard, NBR 9050: 2015 which deals with accessibility to buildings, furniture,
\end{abstract}

1. Curso de Edificações, Departamento de Ensino, Pesquisa e Extensão. Instituto Federal de Santa Catarina - IFSC, Brasil. E-mail: gabriel.bem@ifsc.edu.br

2. Curso de Design, Departamento de Expressão Gráfica, Centro de Comunicação e Expressão Universidade Federal de Santa Catarina - UFSC , Brasil. E-mail: regiane.pupo@ufsc.br 
spaces and urban equipment, the installation of tactile maps is a requirement to be met in public access buildings, however, there are few guidelines regarding to its manufacture, and to the characterization of tactile reliefs. In addition to this, there are divergences on the specifications of the elements among researchers in the area. This paper contributes to social inclusion with as to the teaching of geography, cartographic language and spatial orientation, as it puts together parameters adopted nowadays in Brazil, within the scope of tactile cartography. Moreover, it brings a synthesis of the elements in use in Brazil and abroad related both to cartography and the manufacture of maps for buildings. Besides, it also develops, evaluates and validates, through testing with professional braille proofreaders, new parameters to be shared by tactile map developers. The parameters presented include symbols, letters, lines, textures and braille, characterizing them in terms of thickness, shape, surface elevation and representation patterns, resulting in a pattern of representation and manufacture of symbols for tactile maps.

KEYWORDS: Tactile pattern. Additive manufacturing. Visually impaired.

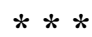

\section{Introdução}

Edificações de acesso público, tais como shoppings, aeroportos, rodoviárias, escolas e universidades, caracterizam-se pelo difícil processo de seleção de informações por parte do usuário, devido ao seu excesso e intenso fluxo de pedestres (DISCHINGER e BINS ELY, 2010). Como consequência, dificulta o seu entendimento espacial e, por conseguinte, a mobilidade dos usuários, em especial daqueles com algum tipo de deficiência. De acordo com Arthur e Passini (2002), a orientação espacial está relacionada à capacidade de uma pessoa determinar a sua localização no espaço, criando um mapa mental, que não é exatamente um mapa, mas uma representação metafórica de um lugar e que contém informações relevantes para a orientação espacial de uma pessoa com deficiência visual.

Dessa forma, fica evidente a necessidade de uma correta informação sobre a organização espacial do entorno, que possibilite aos usuários o desenvolvimento de um percurso autônomo e confiante. Por sua vez, a utilização de instrumentos que simulem a realidade espacial pode 
representar um envolvimento significativamente positivo entre usuário e ambiente (BERNARDI, D'ABREU e KOWALTOWSKI, 2009).

A cartografia tátil demanda um processo de fabricação que leve em consideração aspectos como: custo e benefício, estocagem da matriz tátil, vida útil e produtividade da matriz. Nesse contexto, a aplicação das técnicas de prototipagem digital na fabricação de matrizes táteis tende a somar nesse campo de estudo (LOCH, 2008; FERREIRA e DA SILVA, 2012).

Fabricação digital caracteriza-se como um método automatizado de fabricação que contempla tanto a personalização quanto a customização dos produtos. Pode ser empregada para fabricação de protótipos em pequenas escalas com a finalidade de estudo e avaliação, e até mesmo elementos em escala real (PUPO, 2009). Em virtude das características intrínsecas a algumas técnicas de impressão, (nitidez e acuracidade de representação de texturas, agradabilidade ao tato e resistência ao manuseio), a prototipagem digital apresenta-se como uma maneira de viabilizar a fabricação dos mapas táteis (MILAN e CELANI, 2008; FERREIRA e DA SILVA, 2012; PUPO e ARANDA, 2011).

Dentre os autores relacionados à temática, não há um critério único de representação que contemple símbolos, letras, linhas, texturas e braile, caracterizando-os no que diz respeito à espessura, formato, elevação em relação à superfície e padronagens de representação. Partindo de uma coleta e agrupamento de parâmetros já desenvolvidos e associando-os a novos elementos, essa pesquisa tem como objetivo o desenvolvimento de um padrão de representação de elementos táteis para mapas. Tendo em vista os benefícios associados ao uso da Fabricação Digital na produção de mapas táteis, os critérios aqui apresentados foram reproduzidos com essa tecnologia e avaliados por revisores braile, validando assim a sua caracterização. 


\section{Materiais e métodos}

Há diversos critérios de representação dos elementos táteis em mapas. A fim de se chegar a um parâmetro geral, agruparam-se aqui os principais deles, tendo em vista que não há uma normalização brasileira que contemple todos os elementos.

Para contemplar um maior número de elementos já criados, foram incluídos os símbolos existentes no Catálogo de Símbolos para Mapas Táteis, desenvolvido pelo laboratório de Cartografia Tátil e Escolar da Universidade Federal de Santa Catarina. O catálogo busca uma padronização dos mapas táteis para o Brasil, elaborados no projeto Mapa Tátil como um Instrumento de Inclusão Social de Portadores de Deficiência Visual (LOCH et al., 2007). Os símbolos, criados de maneira artesanal com miçangas, cordonês, cortiça etc., destinam-se aos métodos de fabricação com papel microcapsulado e termoformado, em películas de acetato. Nesta pesquisa, adotou-se a representação desses elementos digitalmente e posterior impressão por intermédio da prototipagem digital.

Dentre as referências consultadas, os parâmetros apresentados aqui dizem respeito às publicações dos autores listados no Quadro 1, cujas contribuições estão detalhadas nos quadros 2 a 25 . 
Quadro 1 - Autores consultados

\begin{tabular}{|c|c|c|c|}
\hline Autor & Contribuição & Autor & Contribuição \\
\hline $\begin{array}{c}\text { Schiff (1966, apud } \\
\text { EDMAN, 1992) }\end{array}$ & $\begin{array}{l}\text { Letras em } \\
\text { relevo, elevação } \\
\text { dos elementos }\end{array}$ & Edman (1992) & $\begin{array}{l}\text { Tipos de linhas, } \\
\text { símbolos de uso, } \\
\text { elevação dos } \\
\text { elementos } \\
\end{array}$ \\
\hline $\begin{array}{l}\text { Angwin }(1968 \mathrm{a} ; \\
\text { 1968b apud } \\
\text { EDMAN, 1992) }\end{array}$ & $\begin{array}{l}\text { Quantidade de } \\
\text { pontos numa } \\
\text { linha }\end{array}$ & Loch et al. (2007) & $\begin{array}{c}\text { Símbolos de uso e } \\
\text { dimensões }\end{array}$ \\
\hline $\begin{array}{c}\text { Widel e Groves } \\
(1969)\end{array}$ & $\begin{array}{c}\text { Elevação dos } \\
\text { elementos }\end{array}$ & Bernardi (2007) & $\begin{array}{c}\text { Emprego de } \\
\text { texturas. }\end{array}$ \\
\hline $\begin{array}{l}\text { Nolan e Moris (1971 } \\
\text { apud EDMAN, 1992) }\end{array}$ & $\begin{array}{l}\text { Símbolos } \\
\text { pontuais }\end{array}$ & Jehoel (2007) & $\begin{array}{l}\text { Tipos, espessura e } \\
\text { formato em corte de } \\
\text { linhas, símbolos } \\
\text { pontuais e } \\
\text { dimensões }\end{array}$ \\
\hline $\begin{array}{c}\text { Jansson (1973 apud } \\
\text { EDMAN, 1992) }\end{array}$ & Texturas & $\begin{array}{c}\text { Nottingham Map Kit } \\
\text { (s.d., apud EDMAN, } \\
\text { 1992) }\end{array}$ & Símbolos de uso \\
\hline $\begin{array}{l}\text { James e Gill (1975, } \\
\text { apud EDMAN, 1992) }\end{array}$ & $\begin{array}{c}\text { Elevação dos } \\
\text { elementos }\end{array}$ & NBR 9050 (2015) & Braile \\
\hline $\begin{array}{c}\text { Bentzen (1983 apud } \\
\text { EDMAN, 1992) }\end{array}$ & Tipos de linhas & - & - \\
\hline
\end{tabular}

Fonte: Adaptado de Bem (2016).

Dentre os autores listados na Tabela 1, apenas três são fontes brasileiras: Loch et al. (2007), Bernardi (2007) e a NBR 9050 (2015), sendo que essa última se restringe aos critérios de representação do braile adotados nesse estudo. Percebe-se a pouca representatividade de autores nacionais no que diz respeito à contribuição com a área de estudo.

\subsection{Caracterizações dos elementos}

Nos subitens a seguir, serão apresentados os critérios para representação de símbolos pontuais e de uso, letras em relevo, braile, linhas e texturas, baseado no agrupamento das especificações obtidas nas produções técnicas dos autores listados na Tabela 1. 
2.1.1 Símbolos pontuais e de uso

A habilidade da pessoa com deficiência visual em reconhecer e compreender símbolos ainda é algo controverso. A frequência com que o usuário fará a leitura desses símbolos depende diretamente da utilização desses mapas, além das habilidades e experiências do leitor (EDMAN, 1992). Para Edman (1992), letras individuais, ou a combinação de mais de uma letra para representação de um elemento, podem ser mais fáceis de compreensão e lembrança do que números ou códigos que levam a constantes verificações na legenda do mapa. O autor ainda sugere que essa combinação de letras tenha relação com o significado do local.

Figuras simbólicas que são utilizadas para representação de locais específicos de objetos, origem de emissores de som ou cheiro são chamados de "símbolos pontuais". Caracteres em braile, ou até mesmo letras em caixa alta, podem ser incluídos nesse grupo. Seu formato não representa necessariamente o real formato do elemento a que se refere (EDMAN, 1992).

Nolan e Morris (1971 apud EDMAN, 1992) indicam alguns exemplos para símbolos pontuais, sem necessariamente indicar um significado, conforme pode ser visto na Figura 1, a mesma utilizada em seus testes realizados.

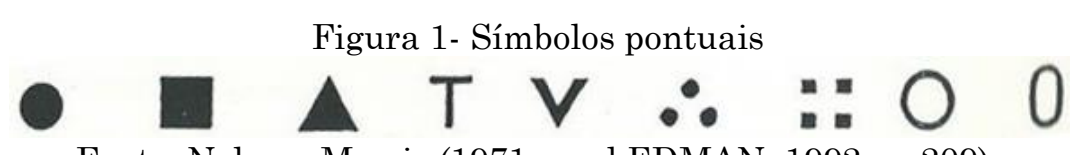

Fonte: Nolan e Morris (1971 apud EDMAN, 1992, p. 209).

Tendo em vista a variedade de símbolos utilizados tanto para fabricação de mapas táteis quanto na cartografia tátil, Jehoel (2007) realizou testes de leitura com 40 símbolos diferentes, a fim de identificar quais deles seriam mais detectáveis. Os elementos são constituídos por círculos, quadrados, triângulos e cruciformes. 
Como resultado, obteve-se uma redução considerável para 11 símbolos, como pode ser visto na Figura 2.

Figura 2 - Símbolos pontuais com melhor detectabilidade

\begin{tabular}{|c|c|c|c|}
\hline$\bigcirc$ & $\square$ & $\sqcap$ & $*$ \\
\hline$\odot$ & $\bigwedge$ & $\bigwedge$ & + \\
\hline$\bigcirc$ & $\Lambda$ & $\bigcap$ & \\
\hline
\end{tabular}

Fonte: Jehoel (2007).

Para avaliação nessa pesquisa foram adotadas as 11 opções apresentadas pela pesquisadora.

\subsubsection{Letras em relevo}

As formas de representação do texto para leitura por pessoas cegas ou com deficiência visual são o braile ou texto em relevo. Um estudo conduzido em Geórgia, no Institute of Technology, College of Architecture, for the Architectural and Transportation Barriers Compliance Board, mostrou que ensinar aos usuários a leitura em relevo tende a ter o mesmo nível de dificuldade de se ensinar a leitura em braile. $\mathrm{O}$ estudo ainda concluiu que a maior parte dos usuários avaliados tiveram dificuldades na interpretação das letras minúsculas (ARTHUR e PASSINI, 2002). Sendo assim, para as letras em relevo sugere-se a representação em caixa alta ou capital letters.

As letras maiúsculas mais utilizadas são A, B, C, E, F, H, I, J, L, Q, P, R, S, T, U, Y e Z. Essas letras foram reconhecidas com maior facilidade em um estudo realizado por Schiff (1966 apud EDMAN, 1992). Na presente pesquisa, essas letras foram representadas com $14,2 \mathrm{~mm}$ de altura. 


\subsubsection{Braile}

De acordo com a Norma Brasileira Regulamentadora, (NBR 9050, 2015), o ponto braile deve ter aresta arredondada na forma esférica. O arranjo dos 6 pontos, sua distribuição em duas colunas e o espaçamento devem respeitar as especificações da norma, conforme Figura 3.

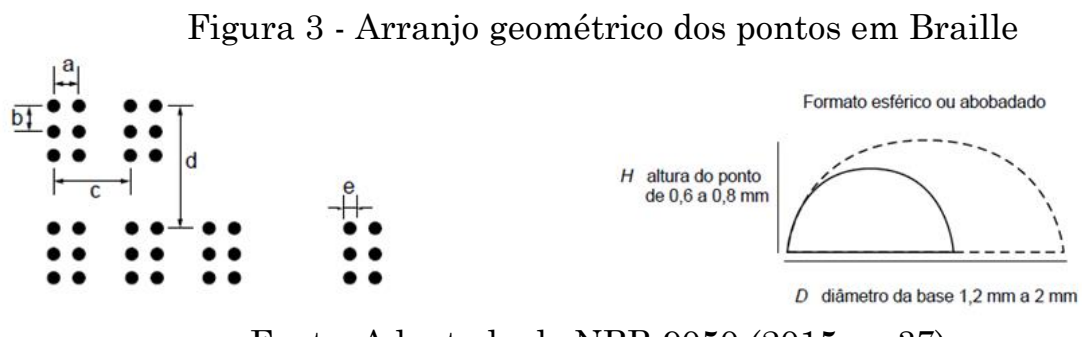

Fonte: Adaptada de NBR 9050 (2015, p. 37).

A tabela 2 abaixo traz as dimensões ilustradas na figura 3 .

Tabela 2 - Arranjo geométrico dos pontos em braile

\begin{tabular}{c|c|c|c|c|c}
\hline $\begin{array}{c}\text { Cota a } \\
(\mathbf{m m})\end{array}$ & $\begin{array}{c}\text { Cota b } \\
(\mathbf{m m})\end{array}$ & $\begin{array}{c}\text { Cota c } \\
(\mathbf{m m})\end{array}$ & $\begin{array}{c}\text { Cota d } \\
(\mathbf{m m})\end{array}$ & $\begin{array}{c}\text { Cota e - Diâmetro da } \\
\text { Base } \mathbf{( m m})\end{array}$ & $\begin{array}{c}\text { Altura do ponto } \mathbf{H} \\
\mathbf{( m m})\end{array}$ \\
\hline 2,7 & 2,7 & 6,6 & 10,8 & de 1,2 a 2,0 & De 0,6 a 0,8 \\
\hline
\end{tabular}

Fonte: Adaptada de NBR 9050 (2015, p. 37).

\subsubsection{Linhas}

As linhas empregadas na representação tátil podem sofrer uma série de variações, tais como: pontilhadas, tracejadas, sólidas, uma composição dessas três características, além de variações na espessura e altura.

Em testes realizados por Bentzen (1983 apud EDMAN, 1992), linhas simples são mais fáceis de leitura e representação mental, se comparadas às linhas duplas. Somado a isso, Edman (1992) destaca o simples fato de as linhas simples ocuparem menos espaço do que as linhas duplas, favorecendo a escala de representação dos elementos. 
Com relação à espessura das linhas, Jehoel (2007) identificou como 1,9 mm a espessura máxima para linhas simples, caso contrário, será percebida como uma linha dupla e o espaçamento mínimo entre linhas duplas deve corresponder a $1,0 \mathrm{~mm}$.

Partindo de 18 tipos de linhas caracterizadas por outros autores como sendo as mais detectáveis, a pesquisadora obteve um novo resultado a partir de seus estudos, reduzindo para 4 as linhas com melhor detectabilidade: linha lisa simples, linhas lisa dupla, linha ondulada e linhas pontilhada dupla. A autora adotou como espessura 1,0 $\mathrm{mm}$ e $0,4 \mathrm{~mm}$ de elevação.

Adotaremos então as quatro formas de representação sugeridas por Jehoel (2007).

\subsubsection{Texturas}

Texturas são utilizadas para diferenciação de superfícies com diferentes significados e auxiliam o usuário a rapidamente identificar os limites de uma área. Sem a textura, o usuário pode ter dificuldade de identificar as linhas limites de determinada demarcação, ou ainda, ter dificuldades para identificar qual área ele está lendo (EDMAN, 1992).

Cabe ressaltar, ainda, que o emprego da textura está relacionado com a diferenciação de elementos de mesmo formato existentes no mapa (BERNARDI, 2007).

Há uma série de características que devem ser levadas em consideração quando da diferenciação das superfícies (EDMAN, 1992), a saber:

a) o grau de organização dos elementos da textura como, por exemplo, o espaçamento dos elementos de forma igual ou desigual;

b) a densidade dos relevos, ou seja, o espaço entre os elementos e a quantidade deles em determinado espaço;

c) a sensação ao toque na superfície (rugoso ou macio);

d) o formato dos elementos constituintes da textura;

e) o tamanho dos elementos; 
f) a direção em que os elementos são representado, horizontal, vertical ou diagonal.

Jansson (1973 apud EDMAN, 1992), sugere 5 tipos de texturas, as quais foram validadas em seus estudos como sendo as mais eficientes. A representação das texturas pode ser vista na Figura 4.

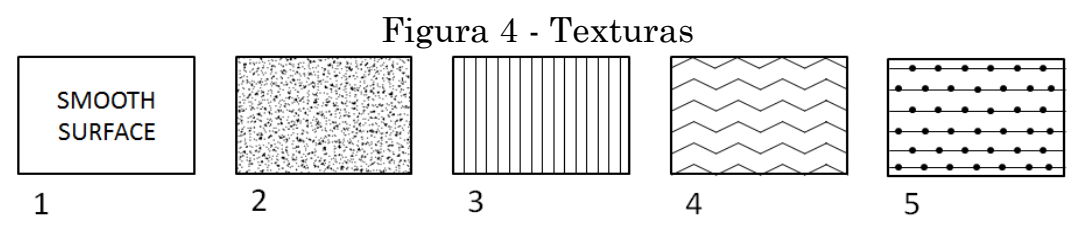

Fonte: Adaptada de Jansson (1973 apud EDMAN, 1992).

Nessa pesquisa, optamos por reproduzir as texturas 1, 3, 4 e 5, pois a textura 2 não possui critério de representação. A textura 1, por sua vez, corresponde à uma área sem relevos. Ainda, adaptamos a textura 5 sendo representada como uma área pontilhada.

\subsection{Fabricação do Protótipo}

A impressão do protótipo foi realizada no Centro de Tecnologia da Informação Renato Archer, em Campinas-São Paulo. Para impressão foi utilizado o equipamento Connex 350 da fabricante Objet-Stratasys. O processo de impressão, a jato de fotopolímeros, baseia-se na deposição do material em camadas, as quais são endurecidas pela exposição à luz ultravioleta.

Além das sugestões dos autores citados, foram inseridos novos padrões adaptando-se os critérios e definidos outros, para elementos que não possuíam referência para sua fabricação.

Com o objetivo de padronizar as características de representação dos elementos com a mesma função, adotaram-se os parâmetros de elevação conforme apresentado na Tabela 3, criando-se uma hierarquização de acordo com o grau de importância dos seus significados. 
Tabela 3 - Critério de representação dos elementos táteis

\begin{tabular}{c|c}
\hline Elemento & Elevação $(\mathbf{m m})$ \\
\hline Linhas & 1 \\
\hline Texturas & 0,5 \\
\hline $\begin{array}{c}\text { Símbolos de uso, símbolos pontuais e letras } \\
\text { em relevo }\end{array}$ & 1,5 \\
\hline Braile & 0,6 e 0,8 \\
\hline
\end{tabular}

Fonte: Bem (2016).

A figura 5 corresponde ao modelo impresso submetido à avaliação pelos revisores braile. Para facilitar o acompanhamento da análise, fez-se uma representação esquemática do protótipo impresso, onde cada elemento recebeu uma numeração.

Figura 5 - Protótipo impresso submetido à avaliação pelos revisores e sua representação esquemática.

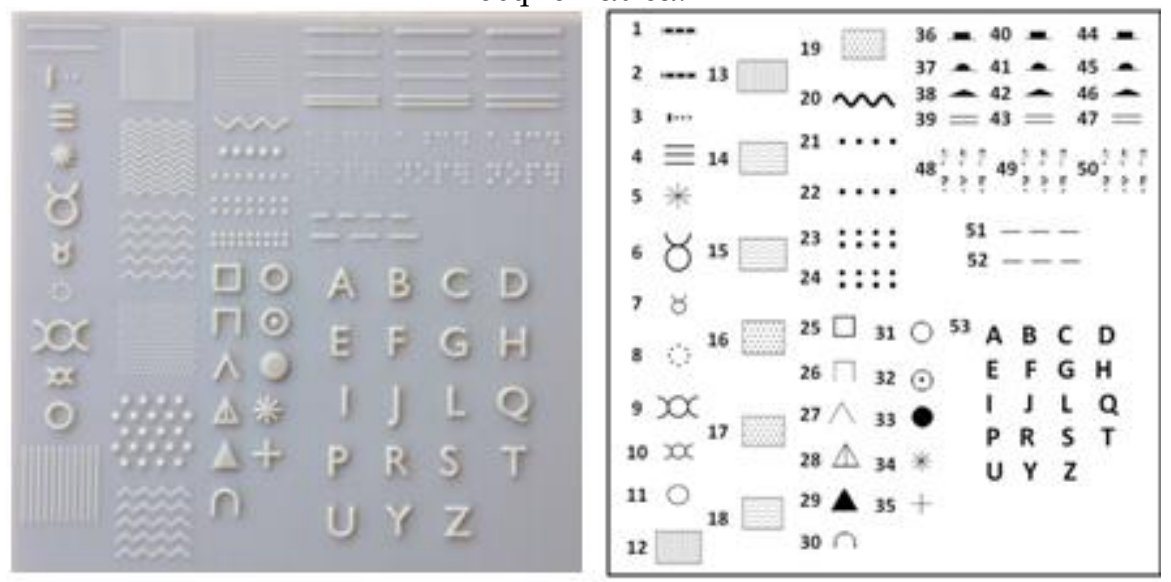

Fonte: Adaptada de Bem (2016).

Maiores detalhes dos elementos impressos podem ser observados na Figura 6, seguindo os parâmetros da tabela 3. 
Figura 6: Detalhes do protótipo impresso

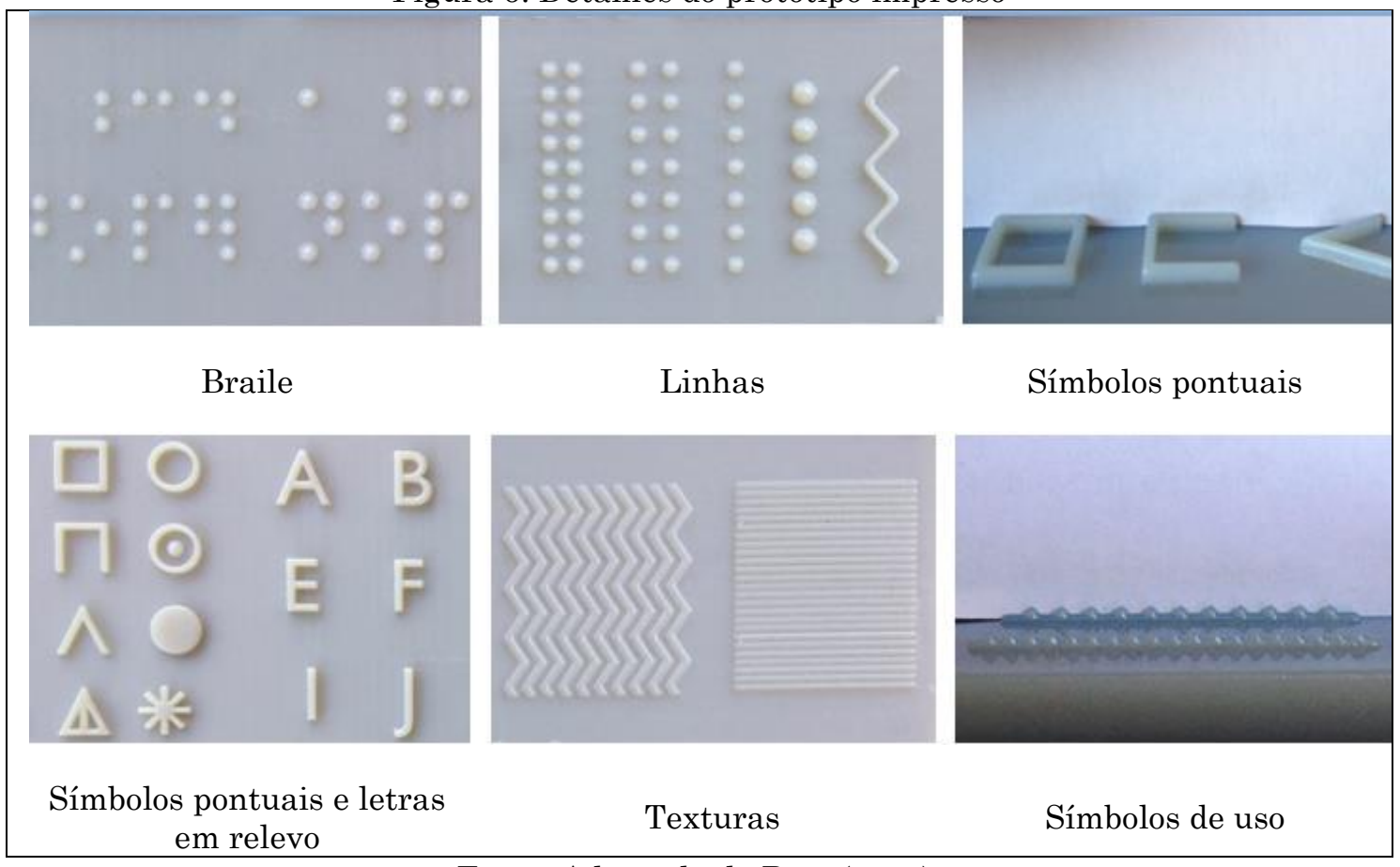

Fonte: Adaptada de Bem (2016).

\subsection{Avaliação do protótipo}

A avaliação dos elementos impressos contou com a participação de 3 profissionais revisores de material braile. Esse processo de análise, que leva em consideração a opinião de pessoas com capacidade de contribuir na solução de um problema, é chamado de painel de especialistas (ELALI e PINHEIRO, 2013). A quantidade de avaliações adotadas está relacionada à representatividade dos envolvidos. Sendo assim, tratando-se de especialistas, optou-se pela quantidade mínima ímpar, maior que um, para caso houvesse empate na escolha dos elementos. Os nomes dos revisores foram substituídos por um conjunto de caracteres a fim de preservar a sua identidade. O conjunto alfa numérico para identificação dos revisores traz consigo as seguintes informações: os dois primeiros números dizem respeito à ordem da avaliação. As duas letras seguintes, CA ou CC dizem respeito à Cegueira Adquirida e Cegueira Congênita, respectivamente. Os próximos dois algarismos dizem respeito à idade do profissional e por fim, as letras $\mathrm{F}$ ou $\mathrm{M}$ correspondem ao sexo Feminino ou Masculino. Ainda que a idade e sexo não fossem 
considerados nos resultados dessas análises, essa nomenclatura pode ser útil para futuras pesquisas, a fim de se identificar possíveis padrões de interpretação atrelados ao sexo ou idade/experiência dos usuários.

O processo de avaliação contou com o consentimento dos participantes por intermédio da assinatura do Termo de Consentimento Livre e Esclarecido, de acordo com a Resolução 466/2012, referente ao projeto CAAE 47786015.9.0000.0121 e Parecer Consubstanciado de aprovação $n^{\circ}$ 1.789.876, junto ao Comitê de Ética em Pesquisa com Seres Humanos da Universidade Federal de Santa Catarina.

O primeiro profissional a realizar a avaliação foi 01CA48M. A cegueira deu-se início aos 22 anos, o que lhe proporcionou a retenção de memória visual. É fluente na leitura em tinta (quando vidente), braile, letras em relevo e mapas táteis. Sua carreira profissional contempla a atuação como assistente técnico pedagógico no Centro de Educação de Jovens e Adultos da capital do Estado de Santa Catarina, Florianópolis, e no setor de revisão de material braile na Fundação Catarinense de Educação Especial, na mesma cidade.

O segundo especialista a analisar o protótipo foi 02CC37F. Sua cegueira é congênita, desde o nascimento, dessa forma, não possui memória visual. Dentre a sua trajetória formativa há a docência na Associação Catarinense para Integração do Cego, também em Florianópolis. Tem fluência na leitura em braile e noção na leitura de tinta em relevo e de mapas táteis.

O terceiro especialista, 03CA35M, sua cegueira é de causa adquirida, originada desde o nascimento, da mesma forma, não possui memória visual. No âmbito profissional sua experiência se dá na revisão de livros em braile no Centro de Produção de Recursos Didáticos para Alunos com Deficiência Visual em Florianópolis. Tem fluência em leitura braile, noção de leitura em tinta em relevo, mapas táteis e mapas cartográficos.

As categorias de análise foram baseadas no estudo conduzido por Jehoel (2007), considerando: sensação ao toque, leveza do material, resistência à manipulação, detectabilidade, legibilidade, espessura, elevação, 
formato em corte, desenho, dimensões e intuitividade. As etapas da análise seguiram um questionário estruturado, no qual o usuário foi conduzido aos elementos impressos e questionado quanto aos respectivos critérios a serem avaliados.

Alguns elementos tiveram mais de uma representação, tendo em vista que não existiam critérios únicos para esses símbolos. Dessa forma, após a análise tátil, foi possível estabelecer uma única tipologia em relação às representações analisadas.

A avaliação dos revisores está dividida dentre os grupos de elementos analisados: símbolos, letras em relevo, braile, linhas e texturas. Os itens analisados são qualificados em: ruim, bom, ótimo ou não se aplica (NSA). Essa última, em função da impossibilidade de aplicação do critério de análise ao respectivo elemento. Ainda, no caso do revisor apresentar alguma consideração, essa é sinalizada com as palavras "sim" ou "não", sendo apresentado logo abaixo da tabela.

As informações estão organizadas da seguinte forma: categoria do elemento, número correspondente ao protótipo impresso (ver figura 5), representação gráfica do símbolo impresso, a fonte pesquisada que deu origem ao elemento, as categorias de avaliação adotadas, as opiniões dos revisores, número correspondente ao elemento escolhido, e, por sua vez, a respectiva representação e o parâmetro resultante sugerido nessa pesquisa.

\subsubsection{Símbolos de Uso e Pontuais}

O primeiro grupo de itens analisados corresponde aos símbolos, tanto de uso quanto pontuais, conforme discriminado nos Quadros 2 a 10. 
Quadro 2 - Símbolos de uso: limite perigoso

\begin{tabular}{|c|c|c|c|c|c|c|}
\hline \multirow{2}{*}{$\mathrm{N}^{\mathbf{o}}$} & \multirow{2}{*}{ Símbolo } & \multirow{2}{*}{$\begin{array}{c}\text { Fonte } \\
\text { Consultada }\end{array}$} & \multirow{2}{*}{$\begin{array}{l}\text { Categorias de } \\
\text { Avaliação }\end{array}$} & \multicolumn{3}{|c|}{ Revisores } \\
\hline & & & & 01CA48M & 02CC37F & 03CA35M \\
\hline \multirow{3}{*}{1} & \multirow[b]{3}{*}{ mence } & \multirow{6}{*}{$\begin{array}{c}\text { Adaptado de } \\
\text { Edman } \\
(1992)\end{array}$} & Melhor opção? & 2 & 1 & 1 \\
\hline & & & Detectabilidade & Ótimo & Ótimo & Ótimo \\
\hline & & & Espessura & Ótimo & Ótimo & Ótimo \\
\hline \multirow{3}{*}{2} & \multirow{3}{*}{$m$} & & Elevação & Ótimo & Ótimo & Ótimo \\
\hline & & & Formato em Corte & NSA & NSA & NSA \\
\hline & & & Observações & Não & Não & Não \\
\hline
\end{tabular}

Fonte: Adaptado de Bem (2016).

Quadro 3 - Símbolos de uso: escada fixa

\begin{tabular}{|c|c|c|c|c|c|c|}
\hline \multirow{2}{*}{$\mathbf{N}^{\mathbf{o}}$} & \multirow{2}{*}{ Símbolo } & \multirow{2}{*}{$\begin{array}{c}\text { Fonte } \\
\text { Consultada }\end{array}$} & \multirow{2}{*}{$\begin{array}{l}\text { Categorias de } \\
\text { Avaliação }\end{array}$} & \multicolumn{3}{|c|}{ Revisores } \\
\hline & & & & 01CA48M & $02 \mathrm{CC} 37 \mathrm{~F}$ & 03CA35M \\
\hline \multirow[b]{3}{*}{3} & \multirow[b]{3}{*}{$\mathbf{I} \cdots$} & \multirow{3}{*}{$\begin{array}{l}\text { Bem (2016). } \\
\text { Adaptado de } \\
\text { James e Gill } \\
\text { (1975, apud } \\
\text { EDMAN, } \\
\text { 1992) }\end{array}$} & Melhor opção? & 4 & 4 & 4 \\
\hline & & & Detectabilidade & Ótimo & Ótimo & Ótimo \\
\hline & & & Elevação & Ótimo & Ótimo & Ótimo \\
\hline \multirow{4}{*}{4} & \multirow{4}{*}{$\overline{\bar{E}}$} & \multirow{4}{*}{$\begin{array}{c}\text { Adaptado de } \\
\text { Loch et al. } \\
(2007)\end{array}$} & Desenho & Bom & Ótimo & Ótimo \\
\hline & & & Dimensões & Ótimo & Ótimo & Ótimo \\
\hline & & & Intuitividade & Ruim & Ruim & Ruim \\
\hline & & & Observações & $\operatorname{Sim}^{1}$ & $\mathrm{Sim}^{2}$ & $\mathrm{Sim}^{3}$ \\
\hline \multicolumn{7}{|c|}{$\begin{array}{l}{ }^{1} \text { Inserir uma seta para cima e uma para baixo, de acordo com a situação e diminuir o } \\
\text { espaçamento entre as linhas. }\end{array}$} \\
\hline \multicolumn{7}{|c|}{$\begin{array}{l}2 \text { Representar as barras com elevação crescente ou decrescente, inserindo um ponto para } \\
\text { localização do usuário em relação à escada. }\end{array}$} \\
\hline
\end{tabular}

Fonte: Adaptado de Bem (2016).

Quadro 4 - Símbolos de uso: sanitário masculino

\begin{tabular}{|c|c|c|c|c|c|c|}
\hline \multirow{2}{*}{$\mathrm{N}^{\mathrm{o}}$} & \multirow{2}{*}{ Símbolo } & \multirow{2}{*}{$\begin{array}{c}\text { Fonte } \\
\text { Consultada }\end{array}$} & \multirow{2}{*}{$\begin{array}{c}\text { Categorias de } \\
\text { Avaliação }\end{array}$} & \multicolumn{3}{|c|}{ Revisores } \\
\hline & & & & 01CA48M & 02CC37F & 03CA35M \\
\hline \multirow[b]{3}{*}{5} & \multirow[b]{3}{*}{ * } & \multirow{3}{*}{$\begin{array}{c}\text { Adaptado de } \\
\text { Nottingham } \\
\text { Map Kit (apud } \\
\text { EDMAN, } \\
\text { 1992) e Jehoel } \\
\text { (2007) }\end{array}$} & Melhor opção? & 6 & 6 & 6 \\
\hline & & & Detectabilidade & Bom & Ótimo & Ótimo \\
\hline & & & Elevação & Ótimo & Ótimo & Ótimo \\
\hline \multirow{2}{*}{6} & & \multirow{4}{*}{$\begin{array}{l}\text { Adaptado de } \\
\text { Loch et al. } \\
\text { (2007) }\end{array}$} & Desenho & Bom & Ótimo & Ótimo \\
\hline & & & Dimensões & Bom & Ótimo & Ótimo \\
\hline \multirow{2}{*}{7} & & & Intuitividade & Ruim & Ruim & Ruim \\
\hline & & & Observações & $\mathrm{Sim}^{4}$ & Não & Não \\
\hline
\end{tabular}

Fonte: Adaptado de Bem (2016). 
Quadro 5 - Símbolos de uso: sanitário feminino

\begin{tabular}{|c|c|c|c|c|c|c|}
\hline \multirow{2}{*}{$\mathbf{N}^{\mathbf{o}}$} & \multirow{2}{*}{ Símbolo } & \multirow{2}{*}{$\begin{array}{c}\text { Fonte } \\
\text { Consultada }\end{array}$} & \multirow{2}{*}{$\begin{array}{c}\text { Categorias de } \\
\text { Avaliação }\end{array}$} & \multicolumn{3}{|c|}{ Revisores } \\
\hline & & & & 01CA48M & 02CC37F & 03CA35M \\
\hline \multirow[b]{3}{*}{8} & & \multirow{3}{*}{$\begin{array}{l}\text { Adaptado de } \\
\text { Nottingham } \\
\text { Map Kit (apud } \\
\text { EDMAN, } \\
\text { 1992) }\end{array}$} & Melhor opção? & 9 & 9 & 9 \\
\hline & & & Detectabilidade & Ótimo & Ótimo & Ótimo \\
\hline & & & Elevação & Ótimo & Ótimo & Ótimo \\
\hline \multirow{2}{*}{9} & & \multirow{4}{*}{$\begin{array}{l}\text { Adaptado de } \\
\text { Loch et al. } \\
\quad(2007)\end{array}$} & Desenho & Bom & Ótimo & Ótimo \\
\hline & & & Dimensões & Ótimo & Ótimo & Ótimo \\
\hline \multirow{2}{*}{10} & & & Intuitividade & Ruim & Ruim & Ruim \\
\hline & & & Observações & $\operatorname{Sim}^{5}$ & Não & Não \\
\hline
\end{tabular}

Quadro 6 - Símbolos de uso: sanitário unissex

\begin{tabular}{|c|c|c|c|c|c|c|}
\hline \multirow{2}{*}{$\mathbf{N}^{\mathbf{o}}$} & \multirow{2}{*}{ Símbolo } & \multirow{2}{*}{$\begin{array}{c}\text { Fonte } \\
\text { Consultada }\end{array}$} & \multirow{2}{*}{$\begin{array}{c}\text { Categorias de } \\
\text { Avaliação }\end{array}$} & \multicolumn{3}{|c|}{ Revisores } \\
\hline & & & & 01CA48M & 02CC37F & 03CA35M \\
\hline \multirow{7}{*}{11} & & \multirow{7}{*}{$\begin{array}{c}\text { Adaptado de } \\
\text { Jehoel (2007) e } \\
\text { Tactual } \\
\text { Mapping } \\
\text { (1986, apud } \\
\text { EDMAN, } \\
\text { 1992). }\end{array}$} & Melhor opção? & NSA & NSA & NSA \\
\hline & & & Detectabilidade & Ótimo & Ótimo & Ótimo \\
\hline & & & Elevação & Ótimo & Ótimo & Ótimo \\
\hline & & & Desenho & Bom & Ótimo & Ótimo \\
\hline & & & Dimensões & Ótimo & Ótimo & Ótimo \\
\hline & & & Intuitividade & Ruim & Ruim & Ruim \\
\hline & & & Observações & Não & Não & Não \\
\hline
\end{tabular}

Fonte: Adaptado de Bem (2016).

Quadro 7 - Símbolos pontuais: quadrados

\begin{tabular}{|c|c|c|c|c|c|c|}
\hline \multirow{2}{*}{$\mathbf{N}^{\mathbf{o}}$} & \multirow{2}{*}{ Símbolo } & \multirow{2}{*}{$\begin{array}{c}\text { Fonte } \\
\text { Consultada }\end{array}$} & \multirow{2}{*}{$\begin{array}{c}\text { Categorias de } \\
\text { Avaliação }\end{array}$} & \multicolumn{3}{|c|}{ Revisores } \\
\hline & & & & 01CA48M & 02CC37F & 03CA35M \\
\hline \multirow{3}{*}{25} & & \multirow{7}{*}{$\begin{array}{c}\text { Adaptado de } \\
\text { Jehoel (2007) e } \\
\text { Edman (1992) }\end{array}$} & Melhor opção? & 25 e 26 & 26 & 26 \\
\hline & & & Detectabilidade & Ótimo & Ótimo & Ótimo \\
\hline & & & Elevação & Ótimo & Ótimo & Ótimo \\
\hline \multirow{4}{*}{26} & & & Desenho & Bom & Ótimo & Ótimo \\
\hline & & & Dimensões & Bom & Ótimo & Ótimo \\
\hline & & & Intuitividade & Ruim & Ruim & Ruim \\
\hline & & & Observações & $\operatorname{Sim}^{6}$ & Não & Não \\
\hline
\end{tabular}

Fonte: Adaptado de Bem (2016). 
Quadro 8 - Símbolos pontuais: triangulares

\begin{tabular}{|c|c|c|c|c|c|c|}
\hline \multirow{2}{*}{$\mathrm{N}^{\mathbf{o}}$} & \multirow{2}{*}{ Símbolo } & \multirow{2}{*}{$\begin{array}{c}\text { Fonte } \\
\text { Consultada }\end{array}$} & \multirow{2}{*}{$\begin{array}{l}\text { Categorias de } \\
\text { Avaliação }\end{array}$} & \multicolumn{3}{|c|}{ Revisores } \\
\hline & & & & 01CA48M & 02CC37F & 03CA35M \\
\hline \multirow{2}{*}{27} & & \multirow{7}{*}{$\begin{array}{c}\text { Adaptado de } \\
\text { Jehoel (2007) e } \\
\text { Edman (1992) }\end{array}$} & Melhor opção? & 27 e 29 & 27 & 29 \\
\hline & & & Detectabilidade & Ótimo & Ótimo & Ótimo \\
\hline \multirow{2}{*}{28} & & & Elevação & Ótimo & Ótimo & Ótimo \\
\hline & & & Desenho & Ótimo & Ótimo & Ruim \\
\hline \multirow{3}{*}{29} & & & Dimensões & Ótimo & Ótimo & Ótimo \\
\hline & & & Intuitividade & Ruim & Ruim & Ruim \\
\hline & & & Observações & $\operatorname{Sim}^{7}$ & $\operatorname{Sim}^{8}$ & Não \\
\hline & & ois ng & impressão de & n triâng & neio, cc & 29. \\
\hline
\end{tabular}

Fonte: Adaptado de Bem (2016).

Quadro 9-Símbolos pontuais: circulares

\begin{tabular}{|c|c|c|c|c|c|c|}
\hline \multirow{2}{*}{$\mathrm{N}^{\mathbf{o}}$} & \multirow{2}{*}{ Símbolo } & \multirow{2}{*}{$\begin{array}{c}\text { Fonte } \\
\text { Consultada }\end{array}$} & \multirow{2}{*}{$\begin{array}{l}\text { Categorias de } \\
\text { Avaliação }\end{array}$} & \multicolumn{3}{|c|}{ Revisores } \\
\hline & & & & 01CA48M & 02CC37F & 03CA35M \\
\hline \multirow[b]{2}{*}{30} & & \multirow{7}{*}{$\begin{array}{l}\text { Adaptado de } \\
\text { Jehoel (2007) e } \\
\text { Edman(1992) }\end{array}$} & Melhor opção? & 31,32 e 33 & 33 & 32 \\
\hline & & & Detectabilidade & Ótimo & Ótimo & Ótimo \\
\hline \multirow{2}{*}{31} & & & Elevação & Ótimo & Ótimo & Ótimo \\
\hline & & & Desenho & Ótimo & Ótimo & Ótimo \\
\hline \multirow{3}{*}{32} & & & Dimensões & Ótimo & Ótimo & Ótimo \\
\hline & & & Intuitividade & Ruim & Ruim & Ruim \\
\hline & & & Observações & $\operatorname{Sim}^{9}$ & Não & Não \\
\hline 33 & & & & & & \\
\hline
\end{tabular}

Fonte: Adaptado de Bem (2016).

Quadro 10 - Símbolos pontuais: cruciformes

\begin{tabular}{|c|c|c|c|c|c|c|}
\hline \multirow{2}{*}{$\mathrm{N}^{\mathbf{o}}$} & \multirow{2}{*}{ Símbolo } & \multirow{2}{*}{$\begin{array}{c}\text { Fonte } \\
\text { Consultada }\end{array}$} & \multirow{2}{*}{$\begin{array}{l}\text { Categorias de } \\
\text { Avaliação }\end{array}$} & \multicolumn{3}{|c|}{ Revisores } \\
\hline & & & & 01CA48M & $02 \mathrm{CC} 37 \mathrm{~F}$ & 03CA35M \\
\hline \multirow{3}{*}{34} & \multirow{3}{*}{ * } & \multirow{7}{*}{$\begin{array}{c}\text { Adaptado de } \\
\text { Jehoel (2007) e } \\
\text { Edman (1992) }\end{array}$} & Melhor opção? & 35 & 35 & 35 \\
\hline & & & Detectabilidade & Bom & Ótimo & Ótimo \\
\hline & & & Elevação & Ótimo & Ótimo & Ótimo \\
\hline \multirow{4}{*}{35} & \multirow{4}{*}{+} & & Desenho & Bom & Ótimo & Ótimo \\
\hline & & & Dimensões & Ótimo & Ótimo & Ótimo \\
\hline & & & Intuitividade & Ruim & Ruim & Ruim \\
\hline & & & Observações & $\operatorname{Sim}^{10}$ & Não & Não \\
\hline
\end{tabular}

Fonte: Adaptado de Bem (2016).

Quanto aos símbolos avaliados, 01CA48M sugeriu a utilização dos símbolos universais de representação de gêneros para os sanitários masculino e feminino. Recomenda a inserção de uma seta para cima ou para baixo na 
representação do símbolo para escada. Já para o símbolo da escada fixa, após a explicação do significado das variações existentes na composição do símbolo 3, desenvolvido por Bem (2016), os revisores 02CC37F e 03CA35M, sugeriram a incorporação dessas características ao símbolo 4, escolhido de forma unânime como a melhor opção.

O revisor 01CA48M sugeriu como significado para o símbolo pontual quadrado, 26, a localização de outro mapa e o símbolo pontual circular, 32, a localização do leitor no espaço físico: "você está aqui".

Já para os símbolos pontuais triangulares, o revisor 01CA48M sugere a exclusão do símbolo 28, por ser semelhante, durante a leitura tátil, ao elemento 29. Ainda para o revisor 01CA48M, o símbolo 30 deve ser excluído por ser semelhante ao símbolo 26 , embora tenham desenhos circulares e retangulares, respectivamente.

Com relação aos símbolos cruciformes, o revisor 01CA48M compara o símbolo 33 ao 34, pela dificuldade de percepção dos espaços existentes entre as linhas, sugerindo, então, a exclusão do símbolo 34 .

Já para representação de entrada de ambientes, os revisores 01CA48M e 02CC37F sugerem o emprego do símbolo pontual triangular, 27.

Destaca-se aqui a construção da memória tátil após a leitura realizada pelos revisores, uma vez que, mesmo na análise de símbolos realizada em momentos distintos (símbolos de uso 5 e 11 e os símbolos pontuais 31 e 34), eles associaram os seus formatos, reforçando assim a restrição quanto à utilização de símbolos de mesmo desenho ainda que com dimensões variadas.

Os resultados das avaliações de símbolos de uso e pontuais são vistos no Quadro 11. 
Quadro 11 - Resultado da avaliação de Símbolos Pontuais e de Uso

\begin{tabular}{|c|c|c|c|}
\hline Resultado & & Símbolo & Parâmetro de Representação \\
\hline $\begin{array}{l}\text { Linha ou } \\
\text { Limite } \\
\text { Perigoso }\end{array}$ & 1 & & $\begin{array}{l}20 \text { Pontos para cada } 25,4 \mathrm{~mm} \\
\text { Espessura das linhas: } 1,0 \mathrm{~mm} \\
\text { Diâmetro do ponto: } 1,0 \mathrm{~mm} \\
\text { Elevação da linha: } 0,5 \mathrm{~mm} \\
\text { Raio do ponto acima da linha: } 0,5 \mathrm{~mm}\end{array}$ \\
\hline Escada Fixa & 4 & 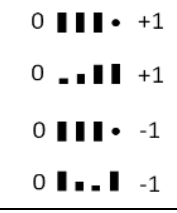 & $\begin{array}{l}\text { Largura total: } 7,1 \mathrm{~mm} \text { / Altura total: } 7,1 \mathrm{~mm} \\
\text { Espessura das linhas: 1,0 mm / Diâmetro ponto: } 1,5 \mathrm{~mm} \\
\text { Espaçamento entre elementos: 2,00 mm } \\
\text { Elevação linha 1: } 0,5 \mathrm{~mm} \text { / Elevação linha } 2: 1,0 \mathrm{~mm} \\
\text { Elevação linha 3: } 1,5 \mathrm{~mm} / \text { Elevação do ponto: } 1,5 \mathrm{~mm}\end{array}$ \\
\hline $\begin{array}{l}\text { Sanitário } \\
\text { Masculino }\end{array}$ & 6 & & $\begin{array}{l}\text { Dimensões (LxA): } 10 \text { x } 15 \mathrm{~mm} \\
\text { Elevação: } 1,5 \mathrm{~mm} \\
\text { Espessura da linha: } 1,0 \mathrm{~mm}\end{array}$ \\
\hline $\begin{array}{l}\text { Sanitário } \\
\text { Feminino }\end{array}$ & 9 & & $\begin{array}{l}\text { Dimensões (LxA): } 10 \text { x } 15 \mathrm{~mm} \\
\text { Elevação: } 1,5 \mathrm{~mm} \\
\text { Espessura da linha: } 1,0 \mathrm{~mm}\end{array}$ \\
\hline $\begin{array}{l}\text { Sanitário } \\
\text { Unissex }\end{array}$ & 11 & & $\begin{array}{l}\text { Diâmetro: } 8,9 \mathrm{~mm} \\
\text { Elevação: } 1,5 \mathrm{~mm} \\
\text { Espessura da linha: } 1,0 \mathrm{~mm}\end{array}$ \\
\hline $\begin{array}{c}\text { Pontual } \\
\text { Quadrado }\end{array}$ & 26 & & $\begin{array}{l}\text { Espessura da linha: } 1,0 \mathrm{~mm} \\
\text { Elevação: } 1,5 \mathrm{~mm} \\
\text { Lado: } 8,9 \mathrm{~mm}\end{array}$ \\
\hline $\begin{array}{l}\text { Pontual } \\
\text { Triangular }\end{array}$ & 27 & & $\begin{array}{l}\text { Espessura da linha: } 1,0 \mathrm{~mm} \\
\text { Elevação: } 1,5 \mathrm{~mm} \\
\text { Lado: } 10 \mathrm{~mm}\end{array}$ \\
\hline $\begin{array}{l}\text { Pontual } \\
\text { Triangular }\end{array}$ & 29 & & $\begin{array}{l}\text { Espessura da linha: } 1,0 \mathrm{~mm} \\
\text { Elevação: } 1,5 \mathrm{~mm} \\
\text { Lado: } 10 \mathrm{~mm}\end{array}$ \\
\hline $\begin{array}{l}\text { Pontual } \\
\text { Circular }\end{array}$ & 32 & & $\begin{array}{l}\text { Espessura da linha: } 1,0 \mathrm{~mm} \\
\text { Elevação: } 1,5 \mathrm{~mm} \\
\text { Diâmetro: } 8,9 \mathrm{~mm} \\
\text { Raio do ponto: } 1,5 \mathrm{~mm} \\
\end{array}$ \\
\hline $\begin{array}{l}\text { Pontual } \\
\text { Circular }\end{array}$ & 33 & & $\begin{array}{l}\text { Espessura da linha: } 1,0 \mathrm{~mm} \\
\text { Elevação } 1,5 \mathrm{~mm} \\
\text { Diâmetro: } 8,9 \mathrm{~mm}\end{array}$ \\
\hline $\begin{array}{c}\text { Pontual } \\
\text { Cruciforme }\end{array}$ & 35 & & $\begin{array}{l}\text { Espessura da linha: } 1,0 \mathrm{~mm} \\
\text { Elevação: } 1,5 \mathrm{~mm} \\
\text { Lado: } 8,9 \mathrm{~mm}\end{array}$ \\
\hline
\end{tabular}

Fonte: Adaptado de Bem (2016).

\subsubsection{Letras em relevo}

Os aspectos avaliados no que diz respeito à representação de letras em relevo, as quais podem ser empregadas em substituição aos símbolos pontuais, pode ser observado no Quadro 12. 
Quadro 12 - Letras em relevo

\begin{tabular}{|c|c|c|c|c|c|c|}
\hline \multirow{2}{*}{$\mathbf{N}^{\mathbf{o}}$} & \multirow{2}{*}{ Símbolo } & \multirow{2}{*}{$\begin{array}{c}\text { Fonte } \\
\text { Consultada }\end{array}$} & \multirow{2}{*}{$\begin{array}{l}\text { Categorias de } \\
\text { Avaliação }\end{array}$} & \multicolumn{3}{|c|}{ Revisores } \\
\hline & & & & 01CA48M & 02CC37F & 03CA35M \\
\hline \multirow{7}{*}{53} & \multirow{7}{*}{$\begin{array}{c}\text { A, B, C, D, } \\
\text { E, F, G, H, I, } \\
\text { J, L, Q, P, R, } \\
\text { S, T, U, Y, Z }\end{array}$} & \multirow{7}{*}{$\begin{array}{c}\text { Adaptado de } \\
\text { Schiff (1966, } \\
\text { apud EDMAN, } \\
19921)\end{array}$} & Melhor opção? & $\begin{array}{l}\mathrm{H}, \mathrm{L}, \mathrm{P}, \mathrm{S} \\
\mathrm{T} \text { e U }\end{array}$ & $\begin{array}{c}\mathrm{A}, \mathrm{C}, \mathrm{D}, \\
\mathrm{E}, \mathrm{F}, \mathrm{G}, \\
\mathrm{H}, \mathrm{I}, \mathrm{J}, \mathrm{L}, \\
\mathrm{Q}, \mathrm{P}, \mathrm{R}, \mathrm{S}, \\
\mathrm{T}, \mathrm{U}, \mathrm{Y} \text { e } \\
\mathrm{Z}\end{array}$ & $\begin{array}{c}\text { A, C, B, D, } \\
\text { E, F, G, H, } \\
\text { I, J, L, Q, } \\
\text { P, R, S, T, } \\
\text { U, Y e Z }\end{array}$ \\
\hline & & & Detectabilidade & Ótimo & Ótimo & Ótimo \\
\hline & & & Elevação & Ótimo & Ótimo & Ótimo \\
\hline & & & Desenho & Bom & Ótimo & Ótimo \\
\hline & & & Dimensões & Ótimo & Ótimo & Ótimo \\
\hline & & & Intuitividade & Ruim & Ruim & Ruim \\
\hline & & & Observações & $\mathrm{Sim}^{21}$ & $\mathrm{Sim}^{22}$ & Não \\
\hline \multicolumn{7}{|c|}{$\begin{array}{l}{ }^{21} \text { Diminuir a espessura das linhas de composição da fonte ou representá-las conforme a } \\
\text { formatação de linhas lisas } 38 \text {. }\end{array}$} \\
\hline \multicolumn{7}{|c|}{${ }^{22}$ Descartar a letra B e o símbolo pontual circular 30, pois é semelhante à letra U. } \\
\hline
\end{tabular}

Fonte: Adaptado de Bem (2016).

Uma sugestão dada por $01 \mathrm{CA} 48 \mathrm{M}$ diz respeito à modificação da espessura das linhas que compõem as letras em relevo, a fim de tornar mais clara a percepção dos espaços existentes no desenho das letras.

$\mathrm{Na}$ da análise das letras em relevo, o revisor 02CC37F sugere a exclusão do elemento 30, por se parecer com a letra 'U' em relevo. Além desse, também sugere a exclusão da letra 'B', devido às características semelhantes à letra 'D'.

Dentre as letras tidas como mais detectáveis, os usuários apontam $\mathrm{H}$, L, P, S, T, U, reduzindo significativamente a quantidade sugerida pelos autores consultados.

O resultado da análise das letras em relevo é apresentado no Quadro 13.

Quadro 13 - Resultado da Avaliação de Letras em Relevo

\begin{tabular}{|c|c|c|l|}
\hline \multicolumn{2}{|l|}{ Resultado } & Símbolo & Parâmetro de Representação \\
\hline $\begin{array}{c}\text { Letra em } \\
\text { Relevo }\end{array}$ & 53 & $\begin{array}{c}\text { H, L, P, } \\
\text { S, T e U }\end{array}$ & $\begin{array}{l}\text { Altura: } 14,2 \mathrm{~mm} \\
\text { Elevação: } 1,5 \mathrm{~mm} \\
\text { Fonte: Arial Regular }\end{array}$ \\
\hline
\end{tabular}

Fonte: Adaptado de Bem (2016). 


\subsubsection{Braile}

A avaliação da representação do braile conforme os parâmetros estabelecidos na Norma Brasileira de acessibilidade podem ser visto no Quadro 14:

Quadro 14 - Braile

\begin{tabular}{|c|c|c|c|c|c|c|c|}
\hline \multirow{2}{*}{$\mathbf{N}^{\mathbf{o}}$} & \multirow{2}{*}{\multicolumn{2}{|c|}{ Símbolo }} & \multirow{2}{*}{$\begin{array}{c}\text { Fonte } \\
\text { Consultada }\end{array}$} & \multirow{2}{*}{$\begin{array}{c}\text { Categorias de } \\
\text { Avaliação }\end{array}$} & \multicolumn{3}{|c|}{ Revisores } \\
\hline & & & & & 01CA48M & $02 \mathrm{CC} 37 \mathrm{~F}$ & 03CA35M \\
\hline \multirow{2}{*}{48} & & & \multirow{6}{*}{$\begin{array}{l}\text { NBR } 9050 \\
(2015) .\end{array}$} & Melhor opção? & 49 & 50 & 50 \\
\hline & $\begin{array}{lll}\infty & \infty & \infty \\
a & b & c \\
\end{array}$ & & & Sensação ao toque & Ótimo & Ótimo & Ótimo \\
\hline \multirow{2}{*}{49} & $: 8:$ & & & Legibilidade & Ótimo & Ótimo & Ótimo \\
\hline & $\begin{array}{lll}a & b & c\end{array}$ & & & Elevação & Ótimo & Ótimo & Ótimo \\
\hline \multirow{2}{*}{50} & $8: 8$ & & & Dimensões & Ótimo & Bom & Ótimo \\
\hline & $\begin{array}{ccc}\infty & \infty & \infty \\
a & b & c \\
\end{array}$ & c & & Observações & Não & $\mathrm{Sim}^{20}$ & Não \\
\hline
\end{tabular}

Fonte: Adaptado de Bem (2016).

Ainda que os três revisores qualificassem as representações em Braile como ótimas, o revisor 02CC37F fez uma observação. Para ele embora os espaços existentes entre as celas braile da terceira representação, 50, fossem pequenos, essa foi a opção mais legível e detectável, se comparada às demais. Dessa forma adotou-se esse critério de representação, conforme Quadro 15.

\begin{tabular}{|c|c|c|c|}
\hline \multicolumn{4}{|r|}{ Quadro 15 - Resultado da Avaliação do Braile } \\
\hline Resul & ado & Símbolo & Parâmetro de Representação \\
\hline Braile & 50 & $\begin{array}{lll}8 & 8 & 8 \\
a & b & c\end{array}$ & $\begin{array}{l}\text { Diâmetro do ponto: } 2,0 \mathrm{~mm} \\
\text { Raio do ponto sobre a superfície: } 0.8 \mathrm{~mm} \\
\text { Distância vertical entre eixo dos pontos: } 2,7 \mathrm{~mm} \\
\text { Distância horizontal entre eixo dos pontos: } 2,7 \mathrm{~mm} \\
\text { Distância vertical entre os primeiros pontos de celas: } 10,8 \mathrm{~mm} \\
\text { Distância horizontal entre os primeiros pontos de celas: } 6,6 \mathrm{~mm}\end{array}$ \\
\hline
\end{tabular}

Fonte: Adaptado de Bem (2016).

\subsubsection{Linhas}

Os parâmetros avaliados referentes à construção das linhas estão divididos nos Quadros 16 a 21, de acordo com o seu tipo. 
Quadro 16 - Formato em corte de linhas lisas

\begin{tabular}{|c|c|c|c|c|c|c|}
\hline \multirow{2}{*}{$\mathbf{N}^{\mathbf{o}}$} & \multirow{2}{*}{ Símbolo } & \multirow{2}{*}{$\begin{array}{c}\text { Fonte } \\
\text { Consultada }\end{array}$} & \multirow{2}{*}{$\begin{array}{c}\text { Categorias de } \\
\text { Avaliação }\end{array}$} & \multicolumn{3}{|c|}{ Revisores } \\
\hline & & & & 01CA48M & $02 \mathrm{CC} 37 \mathrm{~F}$ & 03CA35M \\
\hline \multirow{2}{*}{\begin{tabular}{|c|}
36,40 \\
e 44 \\
\end{tabular}} & & \multirow{6}{*}{$\begin{array}{c}\text { Adaptado de } \\
\text { Jehoel (2007) e } \\
\text { Edman (1992) }\end{array}$} & Melhor opção? & 40 & \begin{tabular}{|l|} 
Indiferente \\
\end{tabular} & 36 \\
\hline & & & Detectabilidade & Ótimo & Ótimo & Ótimo \\
\hline \multirow{2}{*}{$\begin{array}{c}37,41 \\
\text { e } 45\end{array}$} & & & Espessura & Ótimo & Ótimo & Ótimo \\
\hline & & & Elevação & Ótimo & Ótimo & Ótimo \\
\hline \multirow{2}{*}{$\begin{array}{c}38,42 \\
\text { e } 46\end{array}$} & & & Formato em Corte & Ótimo & Ótimo & Ótimo \\
\hline & & & Observações & Não & $\operatorname{Sim}^{15}$ & Não \\
\hline
\end{tabular}

Fonte: Adaptado de Bem (2016).

Quadro 17 - Linhas lisas duplas

\begin{tabular}{|c|c|c|c|c|c|c|}
\hline \multirow{2}{*}{$\mathrm{N}^{\mathbf{o}}$} & \multirow{2}{*}{ Símbolo } & \multirow{2}{*}{$\begin{array}{c}\text { Fonte } \\
\text { Consultada }\end{array}$} & \multirow{2}{*}{$\begin{array}{c}\text { Categorias de } \\
\text { Avaliação }\end{array}$} & \multicolumn{3}{|c|}{ Revisores } \\
\hline & & & & 01CA48M & 02CC37F & 03CA35M \\
\hline \multirow{2}{*}{39} & & \multirow{6}{*}{$\begin{array}{l}\text { Adaptado de } \\
\text { Jehoel(2007) }\end{array}$} & Melhor opção? & 47 & 47 & 47 \\
\hline & & & Detectabilidade & Ótimo & Ótimo & Ótimo \\
\hline \multirow{2}{*}{43} & & & Espessura & Ótimo & Ótimo & Ótimo \\
\hline & & & Elevação & Ótimo & Ótimo & Ótimo \\
\hline \multirow{2}{*}{47} & & & Formato em Corte & NSA & NSA & NSA \\
\hline & & & Observações & Não & Não & Não \\
\hline
\end{tabular}

Fonte: Adaptado de Bem (2016).

Quadro 18 - Linhas tracejadas

\begin{tabular}{|c|c|c|c|c|c|c|}
\hline \multirow{2}{*}{$\mathrm{N}^{\mathbf{o}}$} & \multirow{2}{*}{ Símbolo } & \multirow{2}{*}{$\begin{array}{c}\text { Fonte } \\
\text { Consultada }\end{array}$} & \multirow{2}{*}{$\begin{array}{c}\text { Categorias de } \\
\text { Avaliação }\end{array}$} & \multicolumn{3}{|c|}{ Revisores } \\
\hline & & & & 01CA48M & $02 \mathrm{CC} 37 \mathrm{~F}$ & 03CA35M \\
\hline \multirow{3}{*}{51} & \multirow[b]{3}{*}{---2} & \multirow{6}{*}{$\begin{array}{l}\text { Adaptado de } \\
\text { Edman(1992) } \\
\text { Jehoel (2007) }\end{array}$} & Melhor opção? & 52 & 52 & 52 \\
\hline & & & Detectabilidade & Ótimo & Ótimo & Ótimo \\
\hline & & & Espessura & Bom & Ótimo & Ótimo \\
\hline \multirow{3}{*}{52} & \multirow{3}{*}{-} & & Elevação & Ótimo & Ótimo & Ótimo \\
\hline & & & Formato em Corte & NSA & NSA & NSA \\
\hline & & & Observações & $\operatorname{Sim}^{16}$ & Não & Não \\
\hline
\end{tabular}

Fonte: Adaptado de Bem (2016).

Quadro 19 - Linha ondulada

\begin{tabular}{|c|c|c|c|c|c|c|}
\hline \multirow{2}{*}{$\mathbf{N}^{\mathbf{o}}$} & \multirow{2}{*}{ Símbolo } & \multirow{2}{*}{$\begin{array}{c}\text { Fonte } \\
\text { Consultada }\end{array}$} & \multirow{2}{*}{$\begin{array}{c}\text { Categorias de } \\
\text { Avaliação }\end{array}$} & \multicolumn{3}{|c|}{ Revisores } \\
\hline & & & & 01CA48M & 02CC37F & 03CA35M \\
\hline \multirow{6}{*}{20} & & \multirow{6}{*}{$\begin{array}{l}\text { Adaptado de } \\
\text { Jehoel(2007) }\end{array}$} & Melhor opção? & NSA & NSA & NSA \\
\hline & & & Detectabilidade & Bom & Ótimo & Ótimo \\
\hline & & & Espessura & Ótimo & Ótimo & Ótimo \\
\hline & & & Elevação & Ótimo & Ótimo & Ótimo \\
\hline & & & Formato em Corte & NSA & NSA & NSA \\
\hline & & & Observações & Não & Não & $\operatorname{Sim}^{17}$ \\
\hline
\end{tabular}

Fonte: Adaptado de Bem (2016). 
Quadro 20 - Linha simples pontilhada

\begin{tabular}{|c|c|c|c|c|c|c|}
\hline \multirow{2}{*}{$\mathbf{N}^{\mathbf{0}}$} & \multirow{2}{*}{ Símbolo } & \multirow{2}{*}{$\begin{array}{c}\text { Fonte } \\
\text { Consultada }\end{array}$} & \multirow{2}{*}{$\begin{array}{c}\text { Categorias de } \\
\text { Avaliação } \\
\end{array}$} & \multicolumn{3}{|c|}{ Revisores } \\
\hline & & & & 01CA48M & $02 \mathrm{CC} 37 \mathrm{~F}$ & 03CA35M \\
\hline \multirow{3}{*}{21} & \multirow{3}{*}{$\bullet \bullet \bullet \bullet$} & \multirow{6}{*}{$\begin{array}{l}\text { Adaptado de } \\
\text { Angwin } \\
(1968 \mathrm{a} ; \\
\text { 1968b, apud } \\
\text { EDMAN, } \\
\text { 1992); Widel } \\
\text { e Groves } \\
(1969)\end{array}$} & Melhor opção? & 22 & 21 & 22 \\
\hline & & & Detectabilidade & Bom & Ótimo & Ótimo \\
\hline & & & Espessura & Bom & Ótimo & Ótimo \\
\hline \multirow{3}{*}{22} & \multirow{3}{*}{$\bullet \bullet \bullet \bullet$} & & Elevação & Ótimo & Ótimo & Ótimo \\
\hline & & & Formato em Corte & $\mathrm{NSA}$ & NSA & NSA \\
\hline & & & Observações & Não & Não & $\operatorname{Sim}^{18}$ \\
\hline
\end{tabular}

${ }^{18}$ Poderia utilizar tanto a linha 21 quanto a 22 no mesmo mapa que seriam distinguíveis. Fonte: Adaptado de Bem (2016).

Quadro 21 - Linha dupla pontilhada

\begin{tabular}{|c|c|c|c|c|c|c|}
\hline & & & & & & \\
\hline \multirow{2}{*}{$\mathbf{N}^{\mathbf{o}}$} & \multirow{2}{*}{ Símbolo } & \multirow{2}{*}{$\begin{array}{c}\text { Fonte } \\
\text { Consultada }\end{array}$} & \multirow{2}{*}{$\begin{array}{l}\text { Categorias de } \\
\text { Avaliação }\end{array}$} & \multicolumn{3}{|c|}{ Revisores } \\
\hline & & & & 01CA48M & 02CC37F & 03CA35M \\
\hline \multirow{3}{*}{23} & \multirow{3}{*}{$\because: \bullet:$} & \multirow{6}{*}{$\begin{array}{l}\text { Adaptado de } \\
\text { Jehoel(2007) }\end{array}$} & Melhor opção? & 24 & 23 & 23 \\
\hline & & & Detectabilidade & Bom & Ótimo & Ótimo \\
\hline & & & Espessura & Bom & Ótimo & Ótimo \\
\hline \multirow{3}{*}{24} & \multirow{3}{*}{$\bullet: \bullet \bullet$} & & Elevação & Bom & Ótimo & Ótimo \\
\hline & & & Formato em Corte & NSA & NSA & NSA \\
\hline & & & Observações & $\operatorname{Sim}^{19}$ & Não & Não \\
\hline
\end{tabular}

${ }^{19}$ Espaçamento muito grande entres as linhas da representação 23.

Fonte: Adaptado de Bem (2016).

$\mathrm{Na}$ análise das linhas, o revisor 03CA35M sugere o aumento do número de ondulações no elemento 20 , tendo em vista a possibilidade de percepção de detalhes em uma área menor de representação. Já para linhas tracejadas, o revisor 01CA48M, defende a manutenção do espaçamento existente na linha 52 , independentemente do comprimento destas nos segmentos, pois a percepção da variação dessa linha comparada às lisas se dá pela interrupção do traço seguido do início de outro segmento, importando assim a clara percepção da interrupção da linha. Contudo, para esse mesmo revisor, o maior espaçamento entre os pontos nas variações das linhas duplas pontilhadas prejudica a percepção da continuidade e, consequentemente, a legibilidade com um único tipo de representação. 
De acordo com 03CA35M, os dois tipos de linhas simples pontilhadas, 21 e 22 , poderiam ser utilizados no mesmo mapa, por terem características próprias perceptíveis.

Quanto à análise das variações de formato em corte das linhas, para o revisor 02CC37F a variação foi indiferente na representação, dificultando até mesmo caracterizar dentre as linhas quais delas tinham formatos retangulares e arredondados, além da falsa impressão de que as linhas triangulares fossem linhas retangulares, porém mais finas, mesmo tendo a base mais espessa se comparada à superfície. O conjunto de especificações está agrupado no quadro 22 .

Quadro 22 - Resultado da Avaliação das Linhas

\begin{tabular}{|c|c|c|c|}
\hline \multicolumn{2}{|c|}{ Resultado } & Símbolo & Parâmetro de Representação \\
\hline $\begin{array}{c}\text { Formato em } \\
\text { corte }\end{array}$ & 36 & & $\begin{array}{l}\text { Espessura de } 1,0 \mathrm{~mm} \\
\text { Elevação: } 1,0 \mathrm{~mm} \\
\text { Borda: Retangular }\end{array}$ \\
\hline $\begin{array}{c}\text { Linha Lisa } \\
\text { Dupla }\end{array}$ & 47 & & $\begin{array}{l}\text { Espessura da Linha: } 1,0 \mathrm{~mm} \\
\text { Elevação da Linha: } 1,0 \mathrm{~mm} \\
\text { Distância entre Linhas: } 2,0 \mathrm{~mm}\end{array}$ \\
\hline $\begin{array}{c}\text { Linha } \\
\text { Tracejada }\end{array}$ & 52 & & $\begin{array}{l}\text { Elevação da Linha: } 1,0 \mathrm{~mm} \\
\text { Espessura da Linha: } 1,0 \mathrm{~mm} \\
\text { Tamanho do Traço: } 9,0 \mathrm{~mm} \\
\text { Espaço entre os Traços: } 4,5 \mathrm{~mm}\end{array}$ \\
\hline $\begin{array}{c}\text { Linha } \\
\text { Ondulada }\end{array}$ & 20 & & $\begin{array}{l}\text { Mínimo } 4 \text { cristas e } 4 \text { vales em } 25 \mathrm{~mm} \\
\text { Espessura da Linha: } 1,0 \mathrm{~mm} \\
\text { Distância Externa Entre Crista e Vale: } 4,0 \mathrm{~mm} \\
\text { Elevação da Linha: } 1,0 \mathrm{~mm}\end{array}$ \\
\hline $\begin{array}{c}\text { Linha } \\
\text { Simples } \\
\text { Pontilhada }\end{array}$ & 22 & - & $\begin{array}{l}\text { Diâmetro do Ponto: } 2,0 \mathrm{~mm} \\
\text { Elevação do Ponto: } 1,0 \mathrm{~mm} \\
\text { Distância entre Eixo dos Pontos: } 4,0 \mathrm{~mm}\end{array}$ \\
\hline $\begin{array}{l}\text { Linha } \\
\text { Dupla } \\
\text { Pontilhada }\end{array}$ & 23 & $\bullet \bullet \bullet$ & $\begin{array}{l}\text { Diâmetro do Ponto: } 2,0 \mathrm{~mm} \\
\text { Elevação do Ponto: } 1,0 \mathrm{~mm} \\
\text { Espaçamento Eixo X entre Pontos: } 2,0 \mathrm{~mm} \\
\text { Espaçamento Eixo Y entre Pontos: } 2,0 \mathrm{~mm} \\
\end{array}$ \\
\hline
\end{tabular}

Fonte: Adaptado de Bem (2016).

\subsubsection{Texturas}

Os modelos impressos de texturas e as respectivas avaliações podem ser encontrados nos Quadros 23 a 25. As texturas lisas e rugosas, embora não tenham sido representadas, foram inseridas dentre os resultados. 
Quadro 23 - Textura canelada

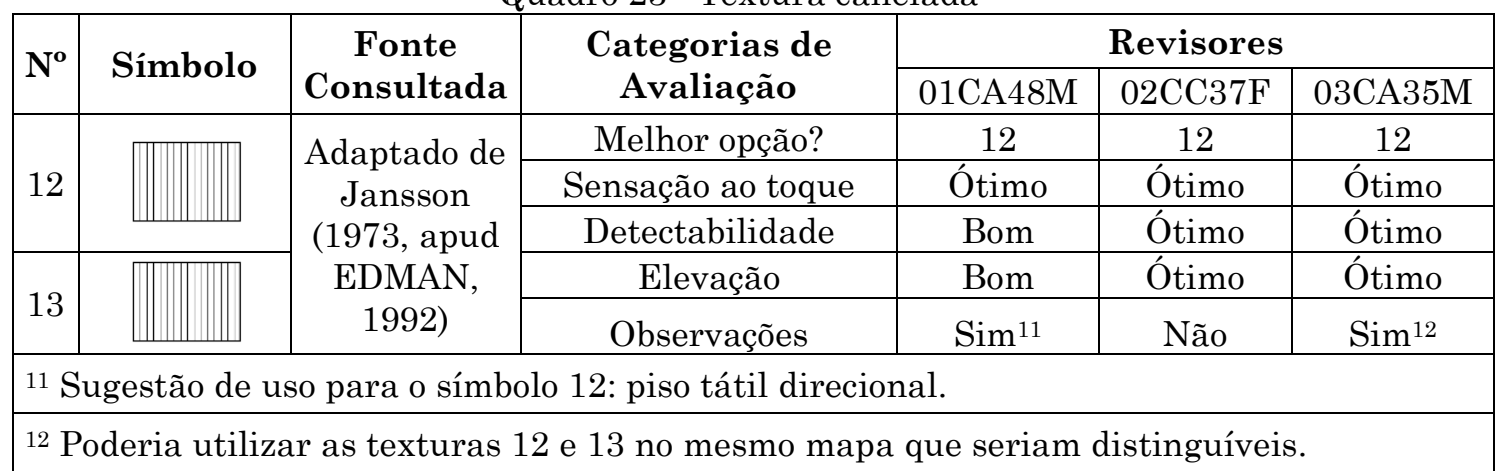

Fonte: Adaptado de Bem (2016).

Quadro 24 - Textura em zigue e zague

\begin{tabular}{|c|c|c|c|c|c|c|}
\hline \multirow{2}{*}{$\mathbf{N}^{\mathbf{o}}$} & \multirow{2}{*}{ Símbolo } & \multirow{2}{*}{$\begin{array}{c}\text { Fonte } \\
\text { Consultada } \\
\end{array}$} & \multirow{2}{*}{$\begin{array}{l}\text { Categorias de } \\
\text { Avaliação }\end{array}$} & \multicolumn{3}{|c|}{ Revisores } \\
\hline & & & & 01CA48M & $02 \mathrm{CC} 37 \mathrm{~F}$ & 03CA35M \\
\hline \multirow{2}{*}{14} & 型网 & \multirow{5}{*}{$\begin{array}{l}\text { Adaptado de } \\
\text { Jansson } \\
\text { (1973, apud } \\
\text { EDMAN, } \\
1992)\end{array}$} & Melhor opção? & 18 & 15 & 15 \\
\hline & aㅗ & & Sensação ao toque & Ótimo & Ótimo & Ótimo \\
\hline \multirow{2}{*}{15} & & & Detectabilidade & Bom & Ótimo & Ótimo \\
\hline & Eas & & Elevação & Bom & Ótimo & Ótimo \\
\hline 18 & 后告 & & Observações & $\operatorname{Sim}^{13}$ & Não & Não \\
\hline
\end{tabular}

Fonte: Adaptado de Bem (2016).

Quadro 25 - Textura pontilhada

\begin{tabular}{|c|c|c|c|c|c|c|}
\hline \multirow{2}{*}{$\mathbf{N}^{\mathbf{o}}$} & \multirow{2}{*}{ Símbolo } & \multirow{2}{*}{$\begin{array}{c}\text { Fonte } \\
\text { Consultada }\end{array}$} & \multirow{2}{*}{$\begin{array}{l}\text { Categorias de } \\
\text { Avaliação }\end{array}$} & \multicolumn{3}{|c|}{ Revisores } \\
\hline & & & & 01CA48M & 02CC37F & 03CA35M \\
\hline \multirow{3}{*}{16} & \multirow{3}{*}{ 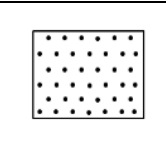 } & \multirow{5}{*}{$\begin{array}{l}\text { Adaptado de } \\
\text { Jansson } \\
\text { (1973, apud } \\
\text { EDMAN, } \\
\text { 1992) }\end{array}$} & Melhor opção? & 19 & 16 & 19 \\
\hline & & & Sensação ao toque & Bom & Ótimo & Ótimo \\
\hline & & & Detectabilidade & Bom & Ótimo & Ótimo \\
\hline \multirow{2}{*}{19} & $\because \because$ & & Elevação & Ótimo & Ótimo & Ótimo \\
\hline & $\because \because \because \because$ & & Observações & $\operatorname{Sim}^{14}$ & Não & Não \\
\hline
\end{tabular}

${ }^{14}$ A representação ainda que se assemelhe a uma lixa, sua rugosidade não causa danos a pele dos dedos. Sugestão de uso para o símbolo 19: representação de piso tátil de alerta.

Fonte: Adaptado de Bem (2016).

Com relação às texturas, o revisor $01 \mathrm{CA} 48 \mathrm{M}$, indicou o uso das texturas 12 e 13 na representação dos pisos táteis direcionais e das texturas 16 e 19 para representação de pisos táteis de alerta, pois compara a percepção tátil da exploração cotidiana de calçadas à representação adotada no protótipo.

A habilidade de detectar os relevos varia para cada revisor, por exemplo, para 03CA35, a texturas 12 e 13 poderiam ser utilizadas 
concomitantemente num mesmo mapa, pois seriam distinguíveis, já para os demais, não seria válido. Ainda, na análise das texturas 14, 15 e 18, apenas o revisor 01CA48M não percebeu a configuração em zigue-zague do elemento. O resultado das análises das texturas é apresentado no Quadro 26.

Quadro 26 - Resultado da Avaliação das Texturas

\begin{tabular}{|c|c|c|c|}
\hline \multicolumn{2}{|c|}{ Resultado } & Símbolo & Parâmetro de Representação \\
\hline $\begin{array}{c}\text { Textura } \\
\text { Canelada }\end{array}$ & 12 & & $\begin{array}{l}\text { Distância entre eixo das linhas: } 2,4 \mathrm{~mm} \\
\text { Espessura das linhas: } 1,0 \mathrm{~mm} \\
\text { Elevação das linhas: } 0,5 \mathrm{~mm}\end{array}$ \\
\hline $\begin{array}{l}\text { Textura em } \\
\text { Zigue-Zague }\end{array}$ & 15 & $\approx$ & $\begin{array}{l}\text { Distância entre crista e vale no eixo x: } 3 \mathrm{~mm} \\
\text { Distância entre crista e vale no eixo y: } 4 \mathrm{~mm} \\
\text { Distância entre linhas: } 3 \mathrm{~mm} \\
\text { Espessura da linha: } 1 \mathrm{~mm} \\
\text { Elevação da linha: } 0,5 \mathrm{~mm}\end{array}$ \\
\hline $\begin{array}{c}\text { Textura } \\
\text { Pontilhada }\end{array}$ & 19 & $\because \because \because 6$ & $\begin{array}{l}\text { Distância Entre Eixo dos Pontos: } \\
\text { Eixo X: 2,00 mm I Eixo Y: 2,00 mm } \\
\text { Distribuição dos Pontos: não radial; } \\
\text { Diâmetro dos pontos: } 1,00 \mathrm{~mm} \\
\text { Raio dos Pontos (elevação): } 0,5 \mathrm{~mm}\end{array}$ \\
\hline
\end{tabular}

Fonte: Adaptado de Bem (2016).

Foi possível perceber que a memória visual do revisor 01CA48M e a experiência profissional como revisor braile de materiais didáticos do revisor 03CA35M foram fatores que influenciaram nas repostas. 01CA48M trouxe mais sugestões para os significados dos símbolos e texturas e 03CA35M destacou a facilidade de deteç̧ão e diferenciação de elementos semelhantes, sugerindo até mesmo o uso simultâneo em um mapa. Além disso, percebe-se que, mesmo tratando-se de uma avaliação realizada por três profissionais atuantes ou com histórico de atuação na área de revisão de material tátil, a avaliação dos elementos difere entre os profissionais.

De maneira geral, a avaliação como ruim para o critério de avaliação intuitividade pode estar relacionada à falta de experiência ou desconhecimento das linguagens de representação de símbolos para mapas táteis. 


\section{Resultados e Discussões}

Como consequência da memória visual nula para alguns revisores, que poderá ocorrer entre os usuários, percebe-se que a associação dos símbolos a significados de forma intuitiva é praticamente inexistente. Por outro lado, a adoção desse critério de avaliação se faz necessária, tendo em vista que na criação de símbolos, a elaboração de elementos que induzam a sua interpretação e a associação a elementos reais, contribuirá na melhoria da compressão dos seus significados por parte das pessoas com deficiência visual.

Baseado na sumária avaliação qualitativa como "bom" e "ótimo" para os quesitos de elevação, detectabilidade, espessura, legibilidade e dimensões, fica comprovado tanto a viabilidade das sugestões dadas pelos autores consultados, quanto à unificação dos critérios para elementos com a mesma função.

Percebe-se ainda que, por se tratar de uma experiência tátil, que tem relação com a experiência de vida do indivíduo, aliada às suas habilidades e sensibilidades desenvolvidas, a aceitação como unânime e ideal de representação é algo difícil de atingir. Como exemplo, são citados os três revisores onde a memória visual e a experiência profissional se mostraram relevantes na configuração das respostas, seja na escolha dos elementos ou nas sugestões de modificações ou indicações de uso. Dessa forma, é sabido que se o material fosse submetido a uma avaliação por usuários sem a mesma habilidade ou acuidade tátil, poderia apresentar-se aquém das expectativas.

\section{Conclusões}

Mediante as avaliações realizadas pelos revisores, foi possível comprovar a viabilidade da caracterização dos elementos táteis sugeridos nesta pesquisa. Destaca-se também que, embora os estudos sobre mapas e maquetes táteis tenham uma expressividade internacional quantitativa superior ao Brasil, ainda assim apresentam critérios distintos de 
representação. Tendo em vista que a norma brasileira vigente não aborda nenhum desses aspectos, espera-se que esses parâmetros possam auxiliar na elaboração de mapas e dispositivos táteis, levando a uma padronização na sua fabricação.

Ainda, é de suma importância que na avaliação de novos símbolos e parâmetros sejam empregadas as categorias de avaliação sugeridas na presente pesquisa, a saber: sensação ao toque, leveza do material, resistência à manipulação, legibilidade, detectabilidade, espessura, elevação, formato em corte, desenho, dimensões e intuitividade. Tais categorias têm por objetivo subsidiar uma análise e uma avaliação mais completa das características perceptíveis pelos usuários, e que estão diretamente relacionadas ao sucesso da definição de novos parâmetros e incorporação dos símbolos nos mapas táteis.

Com o intuito de unificar as simbologias já criadas para alguns elementos na cartografia braile e incorporar símbolos já empregados em outros países, sugere-se que os elementos aqui validados sejam utilizados com os significados apresentados. Para a representação de outros elementos, devese fazer o emprego dos demais símbolos avaliados. Como resultado da redução de alguns elementos, incorporação de outros e a elaboração dos parâmetros de representação de acordo com seus significados, obtém-se assim uma sugestão de padronização de representação. Tais parâmetros tendem a facilitar o processo de leitura e compreensão dos mapas, tendo em vista a viabilidade da sua repetição, contribuindo assim com a inclusão de pessoas com deficiência visual.

\section{Agradecimentos}

Ao Marcelo Fernandes de Oliveira, pesquisador da Divisão de Tecnologias Tridimensionais do Centro de Tecnologia da Informação Renato Archer pela materialização do protótipo e Gilberto Martini, aluno de 
graduação curso de Design da Universidade Federal de Santa Catarina, pelo auxílio na materialização digital do protótipo.

\section{Contribuição dos autores}

Conceptualização (G. M. Bem), análise formal (R. T. Pupo), investigação (G. M. Bem), metodologia (G. M. Bem e R. T. Pupo), administração do projeto (R. T. Pupo e G. M. Bem), recursos e softwares (R. T. Pupo), supervisão (R. T. Pupo), validação (G. M. Bem e R. T. Pupo), visualização (G. M. Bem), redação - minuta inicial (G. M. Bem), redação revisão e edição (R. T. Pupo e G. M. Bem).

\section{Referências}

ANGWIN, J. B. P. Maps for mobility - 1. The New Beacon, v. 52, n. 613, p. 115$119,1968 \mathrm{a}$

ANGWIN, L. B. P. Maps for mobility - 2. The New Beacon, v. 52, n. 613, p. 143154. $1968 \mathrm{~b}$

ARTHUR, P.; PASSINI, R. Wayfinding: people, signs and achitecture. Tornoto: McGraw-Hill Companies, 2002. 238p.

BENTZEN, B. L. Tactile especifications of route configurations. In: WIEDEL, J. W.

Proceedings of the First International Symposium on Maps and Graphics for the Visually Handicapped. p. 125-136. Washington, DC: Association of American Geographers, 1983

BEM, G. M. Parâmetros de fabricação de símbolos para mapas táteis arquitetônicos. Dissertação de mestrado. Universidade Federal de Santa Catarina, Programa de Pós-Graduação em Arquitetura e Urbanismo, Florianópolis, 2016. 204p.

BERNARDI, N. A aplicação do conceito do desenho universal no ensino de arquitetura: o uso de mapa tátil como leitura de projeto. Tese de doutoramento. Universidade Estadual de Campinas, Programa de Pós Graduação em Engenharia Civil, Campinas, 2007. 339 p. 
BERNARDI, N.; D’ABREU, J. V. V.; KOWALTOWSKI, D. C. C. K. Orientação espacial no campus da UNICAMP: diretrizes para o desenvolvimento de um mapa de uso tátil e sonoro como ferramenta de auxílio ao percurso do usuário com deficiência visual. Anais do $\mathbf{1 0}^{\circ}$ Encontro Nacional e $6^{\circ}$ Encontro Latino Americano de Conforto no Ambiente Construído. Natal, 2009. pp. 1827-1830.

DISCHINGER; M.; BINS ELY, V. H. M. Como criar espaços mais acessíveis para pessoas com deficiência visual a partir de reflexões sobre nossas práticas projetuais? In: PRADO, A. R. A. (ed.); LOPES, M. E. (ed.); ORNSTEIN, S. W. (ed.). Desenho universal: caminhos da acessibilidade no Brasil. São Paulo: Annablume, 2010. pp. 95-104.

EDMAN, K. P. Tactile graphics. American Foundation for the Blind, New York, 1992.

ELALI, G. A.; PINHEIRO, J. O. Analisando a experiência do habitar: algumas estratégias metodológicas. In: VILLA, S. B. (ed.); ORNSTEIN, S. W. (ed.) Qualidade ambiental na habitação: avaliação pós-ocupação. São Paulo: Oficina de Textos, 2013. pp. 15-35.

FERREIRA, M. E. DOS S.; DA SILVA, L. F. C. F. Construção de matrizes táteis pelo processo de prototipagem rápida. Revista Brasileira de Cartografia, vol. 64, n.1, 11. 2012. pp. 45-55.

JAMES, G. A.; GILL, J. M. A pilot study on the discriminability of tactile areal and line symbols for the blind. Research Bulletin, n. 29, p. 23-31. New York: American Foundation for the Blind, 1975

JANSSON, G. Projektet PUSS: XVI: linje-och ytsmboler förtaktila kartor. Rapport Nr. 44, Uppsala, Sweden: Psykologiska Institutionen, Uppsala Universitet, 1973

JEHOEL, S.. A series of psychological studies on the design of tactile maps. Doctoral thesis. University of Surrey. Guilford, 2007. $246 \mathrm{p}$

LOCH, R. E. N. Cartografia tátil: mapas para deficiente visuais. Portal da cartografia, vol. 1, n.1, 2008. pp.35-58.

LOCH, R. E. N; NASCIMENTO, R. D. S.; CHAVES, A. P. N.; ALMEIDA, L. C.; ANDRADE, S.; SILVA, C. M. DA; LIMA, G. M. de A.; GOLIN, G.; BULBARELLI, L.; SANTOS, R. F. P. do. Catálogo de símbolos e materiais de 
mapas táteis para mobilidade. In: Catálogo de Materiais ABNT. Universidade Federal de Santa Catarina, 2007. 10 p.

MILAN, L. F.; CELANI, M. G. C. Maquetes táteis: infográficos tridimensionais para a orientação espacial de deficientes visuais. PARC Pesquisa em Arquitetura e Construção, vol. 1, n.2, 2008. pp. 1-26.

NBR 9050: Acessibilidade de pessoas portadoras de deficiência a edificações, espaço, mobiliário e equipamento urbano. Rio de Janeiro: Associação Brasileira de Normas Técnicas, 2015.

NOLAN, C. Y.; MORRIS, J. E. Improvment of tactual symbols for blind children. (Final report Project 5-0421). Louisville, KY: American Printing House for the Blind. 1971

PUPO, R. T. Inserção da prototipagem e fabricação digitais no processo de projeto: um novo desafio para o ensino da arquitetura. Tese de doutoramento. Universidade Estadual de Campinas, Programa de Pós Graduação em Engenharia Civil, Campinhas, 2009. 260p.

PUPO, R. T.; ARANDA, I. M. Sentir um quadro. Anais do $\mathbf{1 5}^{\circ}$ Congresso de la Sociedad Iberoamericana de Gráfica Digital (SIGraDi). Santa Fé, 2011. pp. 1-4.

SCHIFF, W. Manual for the construction of raised line diagrams. New York: Recording for the blind. 1966

WIDEL, J. W.; GROVES, P. A. Tactual mapping: design, reproduction, reading and interpretation. Final Report, Department of Geography. Washington, 1969. $129 \mathrm{p}$. 